\title{
INTERCOMPREENSÃo ENTRE LÍNGUAS Romànicas: Contextos, Perspectivas e Desafios
}

\author{
Regina Célia da Silva*
}

RESUMO: Este artigo visa a caracterizar o contexto no qual a Intercompreensão (IC) surgiu e se desenvolveu enquanto uma das iniciativas de política linguística para a União Europeia que vem ganhando terreno também em outros continentes, respondendo a várias demandas por formação plurilíngue. O artigo busca, em seguida, apontar algumas especificidades do multilinguismo no Brasil e na América Latina, bem como perspectivas e desafios para a IC em sua inserção curricular no contexto universitário brasileiro.

PALAVRAS-CHAVE: intercompreensão; política linguística; currículo.

ABSTRACT: Questo articolo si propone una caratterizzazione del contesto in cui è nata e si è sviluppata l'Intercomprensione (IC) come una delle iniziative di politica linguistica per l'Unione Europea, che tuttavia conquista spazio in altri continenti rispondendo a svariate domande di formazione plurilingue. Cerca anche di analizzare alcune delle specificità del multilinguismo in Brasile e in America Latina, così come alcune prospettive e sfide per l'IC nel suo inserimento nel contesto universitario brasiliano.

PAROLE CHIAVE: intercomprensione; politica linguistica; curriculum.

* Doutora pelo IEL (Unicamp) e docente do CEL-Unicamp. 
ABSTRACT: This article aims to describe the context in which Intercomprehension (IC) was created and developed as one of the language policy initiatives for the European Union. IC is gaining ground in other continents too, responding to various demands for plurilingual education. This paper tries to point out some specific aspects of multilingualism in Brazil and Latin America, as well as perspectives and challenges for IC in its integration in the Brazilian university context.

KEYWORDS: intercomprehension; language policy; curriculum. 


\section{Pressupostos}

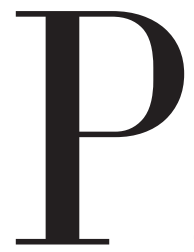

ensar que a uma língua deve corresponde uma nação é uma ideia que nasce em uma determinada fase do capitalismo, fundamentalmente relacionada à formação dos Estados Modernos, ou Estados Nacionais (SILVA, 2012). As Línguas Modernas - nomenclatura usada ainda nos departamentos das universidades aos quais nos vinculamos - são a "herança" de uma determinada concepção de língua e de ensino que serviu e serve ao projeto político da unidade nacional, cujo sucesso dependeu e depende ainda, em grande parte, da unidade linguística.

No Brasil, entre os séculos XVI e XVIII, falava-se o nhangatu, língua geral, sistematizada pelos jesuítas, falada até o século XIX por tribos do litoral brasileiro, e falada ainda hoje por tribos da Amazônia; em 1758, Pombal, representante do governo português, expulsa os jesuítas, 
até então os responsáveis pela catequização dos índios nas línguas locais e também por grandes estudos sobre as línguas indígenas; a partir de então, há a imposição da língua portuguesa, medida considerada necessária para garantir a unidade do território.

Na Itália, durante o fascismo, levou-se adiante uma política a favor do monolinguismo, que, de resto, já era um ideal perseguido a partir da Unificação Italiana, com a proibição dos dialetos, a tentativa de expurgo dos estrangeirismos, o ensino obrigatório da língua italiana em toda a península e a imposição do italiano em todas as instituições ligadas ao Estado.

Diferentemente, na atual fase do capitalismo, as políticas linguísticas apontam na direção do incentivo ao multilinguismo. Embora possa causar estranheza, a língua do atual estágio da globalização não é o inglês (ORTIZ, 2008) ou, ao menos, não é só o inglês. O antropólogo e sociólogo brasileiro Renato Ortiz, ao analisar a alteração das correlações de força entre as línguas no estágio atual da globalização, reconhece que a segmentação e a abertura de novos mercados, bem como a preservação da diversidade cultural e linguística são imperativos para a própria manutenção da ordem mundial do capitalismo em sua fase transnacional.

Nessa mesma direção segue a abordagem de Oliveira (2010) que, em um artigo para a revista Synergie Brasil, intitulado "O lugar das línguas: a América do Sul e os mercados linguísticos da Nova Economia”, sustenta que em cada estágio do capitalismo se constitui uma política linguística.

A geopolítica parece estar mais que nunca na sala de aula de línguas e o momento é oportuno para se refletir sobre um cenário que tem sinalizado para uma significativa mudança de paradigmas no âmbito da didática de línguas.

Podemos tomar como exemplo de novas políticas linguísticas para novos mercados o que tem ocorrido na União Europeia, onde a escolha da(s) língua(s) para um bloco multiétnico teve desdobramentos mais complexos do que a escolha da moeda.

O bloco, em sua configuração atual, é composto por 28 estados, 3 alfabetos e 24 línguas oficiais e de trabalho: alemão, búlgaro, checo, croata, dinamarquês, eslovaco, esloveno, espanhol, estoniano, finlandês, francês, grego, húngaro, inglês, irlandês, italiano, letão, lituano, maltês, neerlandês, polaco, português, romeno e sueco; 75 nacionalidades e uma população que superou a marca dos 500 milhões de habitantes. Entre as línguas oficiais ainda não estão três que são faladas por comunidades bastante numerosas: o catalão, língua materna de cerca de 5 milhões de pessoas e compreendida por outros 10 milhões, na Espanha; o occitano, que designa uma família de línguas faladas por cerca de 10 milhões de pessoas no sul da França e da Espanha e 
que é ensinada em várias escolas; e o sardo, falado por cerca de 2 milhões e meio de pessoas em território italiano.

Em um dos objetivos da Carta de Estrasburgo ${ }^{1}$, de 1992, documento sobre as línguas regionais ou minoritárias do Conselho da Europa, já se acenava para a necessidade de se buscar a unidade na diversidade na qual todos devem ter acesso a uma aprendizagem adequada das línguas para que, em um espírito de solidariedade, possam aceder ao contexto multilíngue.

Em documentos como a Declaração de Barcelona ${ }^{2}$ e a Estratégia de Lisboa ${ }^{3}$, ressalta-se a necessidade de que sejam adotas políticas linguísticas mais abrangentes para a promoção da coesão social e da prosperidade, mediante uma formação plurilíngue que possa minimizar o impacto negativo na economia decorrente da escassez de competências em línguas estrangeiras. Em contexto europeu, a tendência é, portanto, se reiterarem políticas de multilinguismo, pois a manutenção do ecossistema linguístico e cultural tem importância para o equilíbrio das relações econômicas e para a coesão social ${ }^{4}$.

Falar de multilinguismo na América Latina, do ponto de vista da integração dos países do Mercosul, significa falar do português, do espanhol e do guarani, línguas oficiais e de trabalho desse bloco econômico. Todavia, para o mercado linguístico latino-americano e brasileiro, as línguas que têm sido objeto de discussão ampla e para cujo ensino e intercâmbio foram feitos acordos multilaterais são o espanhol - cuja variante predominante para o ensino é, no entanto e paradoxalmente, a peninsular - e o português.

Esse movimento contrasta com a realidade linguística de fato. Apenas no território brasileiro, há, segundo dados do IPHAN, 210 línguas, 30 de imigração e 180 indígenas ${ }^{5}$; entretanto, vários episódios passados e recentes mostraram que a sua preservação, sobretudo no caso das indígenas, não é uma preocupação dos mercados; ao contrário, as identidades cultural e linguística constituem, muitas vezes, um "obstáculo" a ser removido e brutalmente cancelado do mapa.

Por parte do Estado, são relativamente recentes as iniciativas que reconhecem e promovem o multilinguismo autóctone. Levando-se em conta as legislações, somente a última constituição brasileira de 1988 tratou das especificidades da educação em línguas indígenas e do direito desses povos terem acesso à educação formal em seus próprios idiomas, uma medida tardia, sobretudo se considerarmos que as 180 línguas indígenas registradas hoje no país são as sobreviventes

1 Disponível em: http://www.judicatura.com/Legislacion/1527.pdf Acesso em: 12.02.2013.

2 Ver a respeito documento disponível em: http://europa.eu/rapid/press-release IP-12-679 pt.htm acesso em 12.02.2013.

3 Disponível em: http://www.gepe.min-edu.pt/np4/255.html acesso em 12.02.2013.

4 A propósito conferir o documento: Comunicação da Comissão ao Parlamento Europeu, ao Conselho, ao Comité Económico e Social Europeu e ao Comité das Regiões - Multilinguismo: uma mais-valia para a Europa e um compromisso comum. Disponível em:

http://eur-lex.europa.eu/LexUriServ/LexUriServ.do?uri=COM:2008:0566:FIN:PT:HTML. Acesso em 12.02.2013. 5 Conferir dados disponíveis em http://portal.iphan.gov.br/portal/montarDetalheConteudo.do?id=15772\&sigla $=$ Noticia\&retorno= detalheNoticia. Acesso em 13.02.2013. 
entre as 1.500 que aqui existiam na época do início da colonização. O Ministério da Educação do Brasil reconhece 170 línguas indígenas em uso nas comunidades de 210 etnias brasileiras e 2.422 escolas indígenas ${ }^{6}$.

Dentre as línguas de imigração, duas adquiriram o status de "língua" após muita militância de suas comunidades de falantes: o Pomerânio, idioma de parte da comunidade alemã cooficializado no município de Canguçu, em 2010, no Rio Grande do Sul; e o Talian, variante da língua veneta, falada no nordeste da Itália, e também no Brasil, principalmente na região da Serra Gaúcha, no Rio Grande do Sul, e no oeste de Santa Catarina, declarado em 2009, língua co-oficial do município de Serafina Correa.

Esses são dados que mostram brevemente como as políticas linguísticas e o interesse (ou não) pelo plurilinguismo são distintos nos dois hemisférios.

No contexto das políticas linguísticas da União Europeia orientadas para a promoção do plurilinguismo, a IC entre as línguas românicas tem desempenhado um papel de destaque nos últimos $20 \operatorname{anos}^{7}$. Inicialmente. a IC derivou de uma reação à hegemonia do inglês $\underline{\text { CASSEN }}$. 2005), que, desde o final da Segunda Grande Guerra, havia se consolidado como língua mundial unipolar; em seguida, ganhou espaço no âmbito de um movimento de defesa da presença das línguas europeias nas universidades, em instituições públicas, nos currículos e nos meios de comunicação ${ }^{8}$.

No que consiste a IC? De forma alegórica, pode-se dizer que ela promove uma espécie de reversão do mito babélico, segundo o qual o plurilinguismo seria uma maldição, o motivo do desentendimento entre os homens, uma punição lançada por Deus sobre eles, devido à sua soberba e pretensão em buscar aproximar-se dos céus. A IC se pautaria pelo cancelamento dessa maldição, cancelamento, aliás, proposto em outra alegoria da narrativa cristã, a Pentecostes, conforme o qual alguns seguidores de Jesus teriam recebido pelo Espírito Santo o dom das línguas, cinquenta dias após a morte do Redentor. De acordo com a versão dessa narrativa na Bíblia de Jerusalém, os discípulos passaram a ter o "dom" de compreender muitas línguas e de serem compreendidos em sua própria língua. Na competência de falar a própria língua e ser compreendido, sem abdicar da própria identidade, enquanto se compreende(m) a(s) dos demais, em parte, metaforicamente representada no episódio de Pentecostes ${ }^{9}$, consiste o fundamento

6 Conferir dados do censo escolar de 2006 http://portal.mec.gov.br/secad/arquivos/pdf/censosecad.pdf. Acesso em 13.02.2013.

7 A propósito do percurso da IC, ver Anais do Colóquio Intercompréhension: compétences plurielles, corpus, intégration - Université Stendhal Grenoble 3 - Grenoble 2012: http://ic2012.u-grenoble3.fr/index.php?pg=10\&lg=fr.

8 No que se refere à família das línguas românicas, o número de falantes de línguas aparentadas é dado significativo e estimulante para se procurar alternativas para a comunicação entre elas, sem a necessidade de se passar por uma língua franca: Português: 240 milhões (Portugal, Brasil, Moçambique, angola, Guiné Bissau e São Tomé e Príncipe); Espanhol: 500 milhões de falantes, dos quais 400 milhões são falantes nativos; Francês: 300 milhões, dos quais 110 milhões falantes nativos; Italiano: 85 milhões de falantes em todo o mundo; Romeno: 28 milhões na Romênia, Sérvia e Moldávia.

9 Bíblia de Jerusalém. Atos dos Apóstolos, Capítulo 2 versículo 8. Bíblia de Jerusalém, 1985. 
da IC.

Em termos de didática das línguas, a IC é uma prática comunicativa por meio da qual o falante/o aprendiz utiliza seus conhecimentos da língua materna e de outras que conhece para o aprendizado de outras línguas aparentadas, transferindo processos cognitivos e experiências de habilidades adquiridas, dentro de uma língua, para outra de mesma raiz. Pela IC dá-se ênfase ao aprendizado das habilidades receptoras, com foco na compreensão oral e escrita, e não na produção, evitando-se passar por uma língua franca, ou uma terceira língua, quando os interlocutores falam línguas próximas.

A IC se pauta, portanto, pelo contato, pelas transferências, pelo intercâmbio constante entre grupos de língua, pretendendo, assim, assumir como realidade o continuum que existe entre as línguas, algo que as fronteiras políticas não podem apagar (ESCUDÉ e JANIN, 2010).

No Brasil, a IC despertou interesse e ganhou visibilidade a partir de oficinas, encontros de professores de francês, em universidades, em unidades da Aliança Francesa, e em sessões de trabalho com grupos de alunos voluntários realizadas na plataforma Galanet (www.galanet.eu). Implementado em 2004 no contexto das diretrizes de políticas linguísticas da União Europeia reunidas sob Projeto Sócrates Língua ${ }^{10}$, o Galanet promove uma ação pedagógico de formação plurilíngue em um Ambiente Virtual de Aprendizagem (AVA) e visa à pratica da IC entre grupos de falantes de 6 línguas românicas (francês, italiano, português, espanhol, catalão e romeno).

O Galanet é a segunda geração de um percurso de pesquisa-ação denominado afetuosamente por seus participantes de Galasaga; a primeira etapa deste percurso foi o projeto Galatea e a terceira, e última, o projeto Galapro.

O Galatea foi desenvolvido entre 1996 e 1998 e se destina a desenvolver a compreensão da escrita em italiano, francês, espanhol e português por falantes de qualquer uma dessas línguas românicas. Teve como suporte de mídia um CD-Rom ${ }^{11}$ para cada par de línguas, contendo textos "autênticos". Visa a incentivar uma atitude exploratória em relação às línguas românicas com base em suas semelhanças e no uso consciente do conhecimento já possuído de uma língua ou de várias línguas para aprofundar a aprendizagem em outras.

Importa esclarecer que os ambientes da segunda e terceira geração da Galasaga ${ }^{12}$ (Galanet e Galapro) foram concebidos a partir de cenários pedagógicos. Nessas plataformas, o cenário

10 http://ec.europa.eu/education/trainingdatabase/index.cfm? fuseaction=DisplayCourse\&cid=32155\&Language=$\underline{F R}$

11 Esse material está disponível em rede com acesso livre em: http://w3.u-grenoble3.fr/galateal. Acesso em: 12.02.2013.

12 Atualmente, além da geração Gala, há vários manuais e percursos didáticos para o trabalho com IC envolvendo línguas românicas, dentre os quais: Miriadi (Mutualiazação e Inovação para uma Rede de Intercompreensão a Distância), Intermar (aprendizagem de línguas estrangeiras através da intercompreensão em contexto marítimo); Eurom5; EurocomRom; Itinerários românicos; Interlat; InterRom. Cf. também a publicação brasileira: AZEVEDO ( 2011). 
vem configurado em fases, que são as etapas do trabalho a ser desenvolvido em cada sessão ${ }^{13}$.

Em 2005, a IC foi apresentada na Universidade Federal da Paraíba e, em 2007, no Centro de Línguas e Interculturalidade da Universidade Federal do Paraná (CELIN), pelo prof. JeanPierre Chavagne, do Centro de Línguas da Universidade Lumière de Lyon 2. Posteriormente, em 2008, esse mesmo professor ofereceu uma oficina de formação para professores do Estado do Paraná que integrava o projeto Ação para o Letramento criado e coordenado pela professora Lúcia Cherem, do Departamento de Línguas Modernas da UFPR (DELEM), com o apoio do Centro de Ensino de Línguas da Unicamp (CEL) através da professora Rosa Nery e a Secretaria da Educação do Estado Paraná.

O Galanet chegou ao CEL a partir dessa parceria entre as duas universidades. Desde então, iniciei o que considerei um processo de autoformação para o letramento didático-pedagógico digital em ensino de LEs, segundo uma perspectiva plurilíngue, primeiramente como estudante, depois como animadora e redatora, em seguida, como uma das coordenadoras locais da equipe de Campinas e, a partir de 2010, como chefe de sessão. Após a realização da pesquisa de doutorado nessa área, iniciei o processo de abertura de duas disciplinas de IC no Centro de Línguas, que foram ministradas pela primeira vez em 2013.

O processo de validação da inserção da IC na grade curricular de uma Universidade como a Unicamp comportou alguns (curiosos) desafios. Em março de 2009, formamos no centro de línguas um grupo de trabalho multidisciplinar com caráter transversal que reunia professores (uma professora de italiano, uma de espanhol, dois de alemão e uma de francês) com experiência e/ou o interesse em ensino de língua estrangeira a distância. O objetivo era, grosso modo, desenvolver uma alternativa para atender uma demanda crescente por ensino de línguas estrangeiras para alunos da graduação. Nesse projeto transversal, cujo eixo era ensino de língua e virtualidade, inserimos o trabalho em Galanet, em caráter experimental, com participação voluntária dos alunos.

Em 2012, submeti aos Conselhos do Centro e do Instituto de Estudos da Linguagem duas disciplinas de IC entre as línguas românicas, com o suporte da plataforma Galanet. Uma vez aprovadas as ementas, após uma longa tratativa sobre a validade desse "novo conteúdo" junto aos colegas e membros dos respectivos conselhos do centro e do instituto, no momento de "batizar" as disciplinas com uma sigla que corresponda a um lugar no "sistema" da Diretoria Acadêmica

13 Sessão é um período de trabalho na plataforma Galanet que pode durar de dois a quatro meses e se divide em 4 fases. Atuam em uma sessão equipes multilíngues de estudantes coordenados por professores de diversas universidades latino-americanas, europeias e eventualmente de outras partes do mundo. Ao longo de primeira etapa de uma sessão, os participantes elaboram seus perfis, apresentam-se e estabelecem os primeiros contados com membros da própria equipe e de outras; na segunda fase, após a escolha de um tema comum por meio de eleição direta, tem início uma série de discussões em fóruns e chats para a troca de ideias sobre o tema eleito, em várias línguas; posteriormente as equipes se engajam em pesquisas e coleta de documentos que possam fundamentar suas discussões; finalmente, elabora-se coletivamente um documento plurilíngue a ser publicado na página de abertura da plataforma. 
da Universidade, ouvi a seguinte indagação do funcionário responsável: "Professora, a que área pertence essa disciplina?" A pergunta parecia banal e a resposta (ao menos para mim), óbvia: "É uma disciplina das românicas."

Diante do "óbvio", o responsável pela inserção da disciplina no "sistema" se impacientou:

"Mas esta área não existe! É alguma área que já existe que tem que assumir essas disciplinas!"

Tendo em vista o grau de segmentação das áreas e o isolamento das disciplinas, haveria que se "reinventar"/refundar a área das românicas, pois, para o "sistema", e talvez para nós também, ela não existe. Para que a IC ganhe espaço, ela terá que (voltar a?) existir.

No momento da confecção das ementas das disciplinas de IC, o desafio era tentar inseri-las da forma mais abrangente possível de modo que os colegas das outras românicas, caso no futuro se interessem, possam também ministrá-las. Essa foi uma justificativa academicamente pertinente que ganhou a adesão dos membros dos conselhos no momento de se aprovarem as novas disciplinas. Entretanto, paradoxalmente, para o "sistema”, alguma área deveria se responsabilizar pelas disciplinas, pois o "sistema" não prevê um conteúdo multidisciplinar dessa natureza.

Ao final, a grade curricular e o "sistema" parecem se caracterizar como entidades metafísicas que, fundamentalmente, acabam alimentando a inércia e dificultando as mudanças. Mais que um documento ou um conjunto de regras explícitas, o currículo se configura como uma entidade abstrata regida por leis invisíveis, rígidas e imutáveis (SILVA, 2005).

De acordo com suas siglas (LA 138/LA238), as disciplinas de IC estão, na Unicamp, sob a responsabilidade da "área" de italiano e, para todos os efeitos, têm modalidade semipresencial, pois foi assim que o "sistema" pôde "reconhecê-las" dentro do seu paradigma. No catálogo de disciplinas de graduação de 2013 da universidade, as disciplinas de IC “pertencem”, portanto, à "área" de italiano. Não deveria ser assim, se houvesse coerência com o "espírito" da proposta da IC. Mas foi essa a forma possível...

No Brasil, além de uma tradição de ensino de LE pautada no monolinguismo, predomina uma ênfase na modalidade essencialmente presencial de ensino. Apenas em meados dos anos 2000 se deu impulso ao ensino à distância (SILVA, 2012). Entretanto, as orientações dos PCNs (Parâmetros Curriculares Nacionais) são abrangentes o bastante para contemplar propostas interdisciplinares e conteúdos transversais, possibilitando uma abertura para um campo de atuação favorável para iniciativas que fomentem práticas plurilíngues e interculturais.

Para além das questões pedagógicas e didáticas específicas, o percurso de inserção de um novo conteúdo na área de LE está relacionado a um âmbito macroscópico que, em última análise, 
se inscreve no projeto de ensino da universidade e de sua política de ensino de línguas.

Uma questão que está na ordem do dia para as universidades públicas diante do iminente desafio da internacionalização - item responsável inclusive pela queda de algumas de nossas universidades nos rankings internacionais - por meio de programas de mobilidade discente e docente (AUGM, Erasmus Mundus, Ciência sem Fronteiras, entre outros), para os quais não estão minimamente preparadas, é o atendimento a uma demanda por ensino de línguas estrangeiras.

De imediato, no contexto da Unicamp, pode-se afirmar que uma formação para a IC interessa como suporte/apoio para a preparação de alunos para programas de mobilidade estudantil entre alunos de universidades do Brasil e demais países do Mercosul e universidades europeias.

\section{Breves considerações sobre a Intercompreensão na sala de aula}

Uma proposta de ensino plurilíngue em ambiente virtual dessa natureza oferece algumas possibilidades de exploração para múltiplos fins. Com base na observação e na experiência, propusemos como objetivos a serem atingidos por meio das disciplinas de Intercompreensão em contexto universitário os seguintes: 1) Ampliação da compreensão leitora em Língua Estrangeira (LE); 2) Ampliação do letramento digital aplicado à aprendizagem de (LE); 3) Melhoria da produção em língua materna; 4) Experiência e formação para a interculturalidade.

Com o auxílio de um questionário inicial foi possível estabelecer o percurso de formação, o perfil linguístico e as principais metas dos inscritos com relação à disciplina. No nível I de intercompreensão, houve 16 inscritos e 11 concluíram a disciplina. Os alunos eram provenientes dos seguintes cursos: Letras (3); Mestrado em Ciências Políticas (1); Mestrado em Linguística (1); Programa de Formação Interdisciplinar Superior (1); Letras clássicas (2); Linguística (3); Direito (1); Engenharia civil (1); História (1); Física (1); Gestão de políticas públicas (1).

Todos tinham o português como língua materna; dois tinham nível avançado de inglês; os demais tinham conhecimento de, ao menos, outra língua românica (espanhol, francês, italiano). Em linhas gerais, as expectativas e os objetivos dos inscritos eram iniciar o estudo de outras línguas com aproveitamento das já conhecidas; aprofundar e manter as já estudadas e conhecidas.

O material de base utilizado foi o InterRom, método criado por um grupo de professores da Universidade de Córdoba, Argentina, que se baseia na aprendizagem simultânea de habilidades 
receptoras de italiano, português e francês, mediante estratégias cognitivas e metacognitivas destinado ao público adulto de hispanofalantes e materiais didáticos construídos a partir de psicolinguística, da linguística textual, da gramática contrastiva, da didática do plurilinguismo e do construtivismo educativo (MARCHIARO, 2012).

Não é meu objetivo compartilhar com os colegas uma avaliação de forma global e pontual dos resultados obtidos nessa experiência, algo sem dúvida necessário, mas que remeto a outra ocasião. Tomo aqui apenas dois exemplos baseados na observação da dinâmica em sala de aula. A segunda unidade de InterRom enfoca o gênero narrativo e despertou especial interesse nos alunos por possibilitar a leitura de textos literários, com a antecipação (ou inversão) do programa "clássico" dos cursos de línguas românicas. O estudo simultâneo e contrastivo de vários tempos passados em várias línguas permitiu aos alunos realizarem em poucos encontros um "salto" na aprendizagem, pois notaram que, ao "combinarem" as informações das estruturas verbais, sabiam mais do que pensavam saber sobre as línguas.

Outro ponto positivo ressaltado a partir do estudo dessa unidade foi a "(re)descoberta" de autores brasileiros presentes na coletânea cuja leitura abriu um campo para um novo enfoque sobre a língua materna, enquanto uma língua estrangeira; ou seja, o estudo contrastivo de várias línguas aparentadas à língua materna permitiu aos alunos, em certa medida, desnaturalizar a própria língua, a própria literatura, a própria cultura mediante o desvendamento de alguns recursos e mecanismos de (re)construção de sentido, experiência possível no contraponto com a diferença.

\section{Formação para a interculturalidade - o próximo desafio}

"Um filme falado" (2005), do diretor português Manoel de Oliveira, parece ser um excelente contraponto ao mito da nova Europa, que fomenta políticas multiculturais entre seus países membros em uma reação contra-hegemônica, mas estabelecendo internamente suas hegemonias. A trama do filme se desenvolve ao longo de uma viagem de cruzeiro da qual participa um grupo plurilíngue que representaria importantes línguas europeias. Durante o percurso, cada um dos personagens principais se expressa na própria língua e é tranquilamente compreendido pelos demais, sem a necessidade de tradução ou de uso de um idioma intermediário. Irene Papas, Stefania Sandrelli, Catherine Deneuve, John Malkovich (que representa o comandante 
do navio e fala inglês), Leonor Silveira e Filipa de Almeida representam "a si próprios", como ícones de suas respectivas culturas e línguas (grego, italiano, francês, inglês, português). O filme pode ser considerado uma alegoria da formação da UE. O plurilinguismo não chega ser uma maldição, mas o fato de todos se entenderem mutuamente, mesmo cada um falando no seu próprio idioma, não foi o bastante para evitar um fim trágico. A metáfora do navio que explode ao final sugere, provavelmente, a impossibilidade de uma comunidade conviver apenas sob o bom propósito da tolerância das diferenças. O ambiente ingênuo de diálogo simétrico, sem dissonâncias, proposto pelo filme não é suficiente para superar antagonismos, pois o diálogo real entre as diferentes culturas é "sempre competitivo, tenso e difícil" (MAHER, 2007). O maior desafio, atualmente, é conceber recursos e cenários que possam ampliar a formação para a interculturalidade (BALBONI, 2009), um tema, muitas vezes incômodo, que, na prática, ganha uma abordagem ainda periférica predominantemente "motivacional" na aprendizagem de línguas.

\section{Referências}

AZEVEDO, J. C. Gramática comparativa Houaiss, São Paulo: Publifolha, 2011.

BALBONI, P. Per una glottodidattica dell'intercomunicazione romanza. In JAMET, M-C. (ed.). Orale e intercompreensione tra le lingue romanze. Venezia: Le Bricole, 2009.

CASSEN, B. Contra a ditadura do inglês. In Le Monde Diplomatique, Biblioteca Diplô, 2005.

http://diplo.org.br/imprima1069 Acesso: 12/02/2013.

ESCUDÉ, P.; JANIN, P. L'école, la langue unique et l'intercompréhension: obstacles et enjeux de l'intégration. In Synergies Europe, n. 5: 115-125, 2010.

http://ressources-cla.univ-fcomte.fr/gerflint/Europe5/pierre.pdf Acesso: 25/04/ 2011.

MAHER, R. M. Do casulo ao movimento: a suspensão das certezas na educação bilíngue e intercultural. In CAVALCANTI, M. C.; BORTONI-RICARDO, S. M. Transculturalidade, linguagem e educação. Campinas: Mercado das Letras, 2007.

MARCHIARO, S. InterRom: experiencias didácticas y formación en intercomprensión en Argentina. In DEGACHE, C.; GARBARINO, S. (eds.). Actes du Colloque IC2012. Intercompréhension: compétences plurielles, corpus, intégration. Université Stendhal Grenoble 3 (France), 21-22-23, juin 2012. http://ic2012.u-grenoble3.fr/OpenConf/papers/37.pdf Acesso: 13/02/2013. 
MINISTÉRIO DA EDUCAÇÃO. Secretaria de Educação Fundamental. Parâmetros curriculares nacionais: terceiro e quarto ciclos do ensino fundamental - Português. Brasília, DF, 1997.

OLIVEIRA G. M. O lugar das línguas: a América do Sul e os mercados linguísticos da Nova Economia. In Synergies Brésil, $\mathrm{n}^{\mathrm{o}}$ spécial, 2010.

ORTIZ, R. A diversidade dos sotaques: o inglês e as ciências sociais. São Paulo: Editora Brasiliense, 2008.

SILVA, R. C. Plurilinguismo em ambientes virtuais de aprendizagem: potencialidades, entraves, desdobramentos, perspectivas. 2012. Tese (Doutorado em Letras). Campinas: Unicamp, 2012.

http://www.bibliotecadigital.unicamp.br/document/? code $=000849496$

SILVA, T. T. Currículo: uma questão de saber, poder e identidade. Belo Horizonte: Editora Autêntica, 2005 . 